\title{
VALLE-INCLÁN E A INVENÇÃO DE SI
}

VALLE-INCLÁN AND THE INVENTION OF SELF

\author{
Raquel da Silva Ortega \\ Universidade Estadual de Santa Cruz \\ Ilhéus, BA - Brasil \\ ORCID 0000-0003-1117-931X
}

\section{Resumo}

Tentar diferenciar as histórias inventadas das histórias reais sobre a vida do escritor espanhol Ramón del Valle-Inclán (1866-1936) não é tarefa fácil. De fato, o próprio escritor colaborou de maneira ativa e intencional no processo de fabulação sobre sua vida pessoal. O objetivo deste estudo é analisar as biografias sobre Valle-Inclán, verificando como o autor, conscientemente, se movimentava entre as categorias biografia, autobiografia e autoficçáo. Tomando como referência o posicionamento de Valle-Inclán sobre o evento histórico do Carlismo, na vida pessoal e na ficção e com base nas ideias de Alberca (2007), Arfuch (2010) e Lejeune (2014), concluímos que Valle-Inclán criou uma narrativa ficcional para sua vida pessoal, atuando como um personagem conservador, histriônico, extravagante. A estética do esperpento, de sua própria autoria, contribui no processo de criação ficcional de si.

Palavras-chave: Valle-Inclán; Biografia; Autobiografia; Autoficção.

\begin{abstract}
Trying to differentiate the invented stories from the actual stories about the life of the Spanish writer Ramón del Valle-Inclán (1866-1936) is no easy task. In fact, the writer collaborated actively and intentionally in the process of fable over his personal life. The aim of this study is to analyze the biographies on Valle-Inclán, verifying how the author consciously moved himself between the categories biography, autobiography and autofiction. Taking as reference the positioning of Valle-Inclán on the historic event of Carlism, in personal life and in fiction and based on the ideas
\end{abstract}

\section{Resumen}

Intentar diferenciar las historias inventadas de las historias reales sobre la vida del escritor español Ramón María del Valle-Inclán (1866-1936) no es una tarea fácil. De hecho, el propio escritor colaboró de manera activa e intencional en el proceso de fabulación sobre su vida personal. El objetivo de este artículo es analizar las biografías sobre Valle-Inclán, verificando como el autor, conscientemente, se movía entre las categorías biografía, autobiografía y autoficción. Tomando como referencia la posición de Valle-Inclán sobre el evento histórico del Carlismo, en la vida per- 
of Alberca (2007), Arfuch (2010) and Lejeune (2014), Valle-Inclán created a fictional narrative for your personal life, serving as a conservative character, extravagant, histrionic. The aesthetics of the esperpento, of your own devising, helps in the process of creating fictional himself.

Keywords: Valle-Inclán; Biography; Autobiography; Autofiction. sonal y en la ficción y con base en las ideas de Alberca (2007), Arfuch (2010) y Lejeune (2014), concluimos que Valle-Inclán creó una narrativa ficcional para su vida personal, actuando como un personaje conservador, histriónico y extravagante. La estética del esperpento, de su autoría, contribuye en el proceso de creación ficcional de sí.

Palabras clave: Valle-Inclán; Biografía; Autobiografía; Autoficción.

A figura do escritor espanhol Ramón del Valle-Inclán (18661936) está envolvida em uma aura de fábulas. A sua aparência física, com sua longa barba, óculos estilo quevedo, a falta de um braço e o seu comportamento histriônico e errático inspiraram todo tipo de histórias fantasiosas sobre o autor.

Joaquín del Valle-Inclán, neto do escritor, publica o livro intitulado Entrevistas (2000), no qual reúne as entrevistas concedidas pelo seu avô. Seu objetivo, ao recuperar esses textos, era tentar eliminar ou esclarecer as histórias fantasiosas continuamente contadas (VALLE-INCLÁN, 2000, p. 08).

No entanto, ao longo do processo de levantamento dos textos, Joaquín del Valle-Inclán percebe a impossibilidade de realizar o seu objetivo, uma vez que vários entrevistadores confessaram ter publicado entrevistas falsas com o escritor ou terem manipulado entrevistas reais para ampliar seus textos. Por último, admite que seu avô contribuía para alimentar as fábulas em relação a sua própria imagem: "Finalmente, para acabar con los contras, está claro que, algunas veces, don Ramón se equivoca al hablar de su vida - sobre lo primero que escribió, sin ir más lejos -, que le toma el pelo al entrevistador o que se deja llevar por la fantasía." (VALLE-INCLÁN, 2000, p. 09).

De fato, o neto de Valle-Inclán atribui, em outras ocasióes, ao seu avô o processo de fabulação da sua imagem:

"Valle-Inclán era además una persona fantasiosa, se dejaba llevar por la fantasía y dice cosas que sabemos con total cer- 
teza que no son verdad", admitió Joaquin del Valle-Inclán, quien no llegó a conocer a su abuelo pero que lleva años estudiándolo. Desde su nacimiento hasta otros muchos detalles de su vida "él fabuló y las anécdotas son en parte fruto de su fantasía, que después han ido reproduciéndose más de medio siglo", añadió. (EFE, 2015).

A leitura das entrevistas reunidas do livro, efetivamente, não contribui para o esclarecimento do que seria fabulação ou seria a verdadeira imagem de Valle-Inclán. É interessante observar, já em um primeiro contato com os textos, que o formato das entrevistas se aproxima mais de um texto narrativo ficcional do que uma entrevista, uma vez que praticamente todos possuem título, narração, descrição e inferências subjetivas. A título de exemplo, mencionamos a entrevista realizada por Luis Antón del Olmet e publicada no periódico $E l$ Mundo, em 1910. A entrevista é intitulada El Marqués de Bradomín e começa com a descrição da criada que o atende. Quando chega Valle-Inclán, o entrevistador faz uma pergunta relacionada à candidatura do autor como deputado carlista. A partir daí segue-se uma conversa sobre política, que em determinado momento é omitida pelo entrevistador para contar suas impressóes pessoais e subjetivas, gerando um texto descritivo e poético:

\section{$[\ldots]$}

Estamos en plena novela.

El poeta divaga. Por los balcones entra una luz discreta y amable. En el jardin, como en el huerto florido de un pazo, hay unos árboles verdes y cantan en el silencio de la tarde unos pájaros bulliciosos. Dentro de la instancia, todo evoca tempos remotos: los tripticos de asuntos medievales, los retablos con Cristos visigóticos, la grave, la austera, la hidalga catadura del marqués de Bradomín, que supo conmover a toda una generación con la música preciosa de sus páginas inmaculadas, como no se escribieron iguales en lo antaño $y$ como acaso no se escriban en lo venidero.

El poeta sueña, divaga, improvisa. Su ingenio hace realidad una ficción dorada y llena de poesía. Yo, mudo, escucho la fragrante voz de Valle-Inclán. (VALLE-INCLÁN, 2000, p. 16). 
Por mais que Valle-Inclán se dedique a divagar sobre a política espanhola, não há nada no que é apresentado pelo entrevistador que o vincule ao personagem das Sonatas. Ainda assim, o entrevistador intitula a entrevista como El Marqués de Bradomín e finaliza seu texto de maneira poética e simbólica, o que sugere que ele escreve mais sobre o que desejava ou acreditava ver do que sobre o que Valle-Inclán efetivamente apresentou durante o encontro.

Considerando os processos de fabulaçáo que envolvem a figura de Valle-Inclán, utilizados por ele ou por terceiros, tentaremos compreender que papel Ramón del Valle-Inclán assumia para si próprio. Procederemos, entáo, a definir brevemente as categorias biografia, autobiografia e autoficçáo para, em seguida, entender como o autor, de maneira consciente, se movimentava, na sua vida pessoal e na sua escrita, por estes campos.

\section{Valle-Inclán e suas biografias}

A narrativa de vidas náo-ficcionais náo é recente. De fato, remonta à Antiguidade. Acredita-se que o neoplatônico Damaskios criou a expressão biografia (bio, vida e gráphein, escrever, descrever, desenhar) no século V antes de Cristo. Carino (1999) acredita que o sucesso e a permanência no tempo deste gênero ocorrem pelo fascínio que as vidas podem despertar e pela ideia de que cada indivíduo é único e suas trajetórias são especiais e inspiradoras (CARINO, 1999, p. 154). De acordo com o autor, os períodos históricos determinam a apreciação das vidas que serão narradas:

[...] tempos históricos exigem a biografia de heróis; tempos românticos exigem que as vidas retratadas exibam romantismo; épocas históricas regidas pelo condão da fé exigem que as biografias seja hagiografias, retratando a pureza e a retidão dos santos (CARINO, 1999, p. 157).

Além do contexto histórico, o grau de admiração do escritor da biografia em relação à pessoa que está tendo sua vida narrada também será determinante na conduçáo do texto, não sendo, para o autor, possível eliminar as marcas de subjetividade quando há um grau elevado de admiração: 
Embora as apologias proliferem, seus autores preferem tentar esconder-se (sem êxito) por detrás de uma pretensa neutralidade. Quando a admiração pelos biografados é forte a ponto de tornar-se incontrolável, os biógrafos preferem renunciar a qualquer distanciamento crítico e deixam-se levar, satisfeitos e gozosos, pelas ondas arrebatadoras de sua paixão, tornando-se cegos (como qualquer apaixonado) e chegando muitas vezes a naufragar no ridículo. Em verdade, o que fazem são "hagiografias", cuidando, eles mesmos, de canonizar seus biografados (CARINO, 1999, p.155).

Apesar da sua existência de longa data, as biografias atuais são resultado de questóes inerentes às questôes da modernidade, como bem pontua Leonor Arfuch em seu livro $O$ espaço biográfico: dilemas da subjetividade contemporânea (2010). A autora situa a biografia atual no âmbito das discussóes que surgem na metade dos anos 1980 , momento em que os debates sobre um possível fim da modernidade e o surgimento de uma nova inscrição discursiva nomeada como pós-modernidade, aparentemente superadora da modernidade, nas palavras da autora, e que inspiraram novos enfoques de escrita:

[...] a crise dos grandes relatos legitimadores, a perda de certezas e fundamentos (da ciência, da filosofia, da arte, da política), o decisivo descentramento do sujeito e, coextensivamente, a valorização dos "microrrelatos", o deslocamento do ponto de mira onisciente e ordenador em benefício da pluralidade de vozes, da hibridização, da mistura irreverente de cânones, retóricas, paradigmas e estilos (ARFUCH, 2010, p. 17).

Nessa nova perspectiva, o enfoque do sujeito (não necessariamente o da razão) ganha protagonismo em detrimento dos grandes sujeitos e textos coletivos (ARFUCH, 2010, p. 18).

Desde a sua morte, Ramón del Valle-Inclán foi inspiração para várias biografias. Comentaremos brevemente as primeiras, publicadas poucos anos após a sua morte e as últimas, publicadas recentemente. 
Em seu estudo, Martínez Saura (2015), que era contemporâneo de Ramón del Valle-Inclán, apresenta uma análise de várias biografias sobre Valle-Inclán publicadas na sua época, com o objetivo de recolher nesses textos informaçóes anteriores à época em que conheceu o autor.

A primeira biografia foi escrita por Melchor Fernández Almagro e publicada em 1943, sete anos após a sua morte. Tinha como título Vida y literatura de Valle-Inclán e foi publicada pela Editora Nacional, que era o veículo oficial de divulgação do franquismo. De acordo com Martínez Saura (2015), o momento e o veículo nos quais esta biografia surge são significativos, porque a biografia tende a apresentar Valle-Inclán como um bastião do franquismo (MARTÍNEZ SAURA, 2015, p. 257).

A segunda biografia apresenta um enfoque diferente. Foi escrita por Ramón Gómez de la Serna e publicada em 1944 (um ano após a primeira) na América, para a Espalsa Calpe-Argentina, Buenos Aires e México. Nesta biografia, o biógrafo demonstra uma franca admiração por Valle-Inclán na sua escrita (MARTÍNEZ SAURA, 2015, p. 257). Martínez Saura apresenta ainda mais três textos menores, aos quais não nos dedicaremos, uma vez que repetem os mesmos aspectos dos dois primeiros textos, ou seja, estấo influenciados pelas questóes políticas da época e pelo filtro subjetivo da admiração pelo autor.

Trazendo o olhar para os dias atuais, vemos que nos últimos anos foram publicadas duas biografias ${ }^{1}$ sobre Valle-Inclán que atraíram a atenção de estudiosos do escritor, escritas por Manuel Alberca, catedrático da Universidad de Málaga que se dedica a pesquisar sobre autobiografia e autoficção, além de estudar a vida e a obra de Valle-Inclán. Em co-autoria com Cristóbal González, publica a obra Valle-Inclán. La fiebre del estilo (2002). Nesta obra, os autores afirmam que o objetivo do seu estudo é revelar o homem inventor do seu pró-

1 Há, ainda, uma terceira biografia publicada recentemente, intitulada Ramón del Valle-Inclán. Genial, antiguo y moderno (2015), escrita por Joaquín del Valle-Inclán, da qual não trataremos no corpo da pesquisa por não termos tido acesso ao texto da mesma. No entanto, de acordo com a crítica e com entrevistas concedidas, por um lado, o biógrafo peca por não entender que as lendas que envolvem a figura do autor cobram mais sentido que sua vida real, constantemente reivindica uma familiaridade com um avô que nunca conheceu pessoalmente (VILLENA, 2015), por outro, reafirma, como todos os biógrafos de Valle-Inclán, a filiação incondicional do autor com o carlismo (PASTORIZA, 2015). 
prio mito (ALBERCA; GONZÁLEZ, 2002, p. 12). No entanto, no mesmo texto introdutório em que explicitam seu objetivo, os autores reafirmam a impossibilidade de dissociar Valle-Inclán das lendas que o cercam, ao recorrer, por exemplo, à tarefa proposta por Antonio Machado:

En fin, nos gustaría acometer la tarea que Antonio Machado señalase en los años treinta del siglo pasado: "Cuando se haga un día la verdadera epopeya de Valle-Inclán, se empleará el copioso anecdotario de su vida, no para enterrar al escritor bajo un diluvio de hechos insignificantes, sino para dar un poco de luz a la más honda raiz de su personalidad" (ALBERCA; GONZÁLEZ, 2002, p. 13).

É significativo que Machado se refira ao gênero epopeia como uma possível biografia de Valle-Inclán, o que evidencia o carácter ficcional da vida do autor. De todos modos, a proposta de depreender a vida de Valle-Inclán a partir de suas anedotas mostra novamente a impossibilidade de tratar a vida de Valle-Inclán de maneira objetiva.

Por último, Alberca e González afirmam ainda que não pretendem entrar no mérito da análise da obra de Valle-Inclán. Contudo, os capítulos da biografia seguem os títulos e a ordem de publicação das suas obras, o que de certa forma vincula a vida do autor à sua produção escrita, o que não deixa de ser uma análise da produção literária, uma vez que vincula a vida do autor à sua obra.

Esta biografia apresenta um capítulo específico sobre o carlismo. Nele, os autores relatam a viagem que Valle-Inclán faz pela Navarra e salienta a emoção que o autor sentiu ao pisar aquelas terras (ALBERCA; GONZÁLEZ, 2002, p.122-123). Ao apresentar a discussão sobre carlismo por convicção $\mathrm{x}$ carlismo por estética, os biógrafos acreditam resolver a questão deduzindo que ele é carlista por convicção por ser um fervoroso defensor da tradição e saudoso das antigas glórias familiares:

He visto el cambio de una sociedad de castas (los hidalgos que conoci de rapaz), y lo que vi no lo verá nadie. Soy el historiador de un mundo que morirá conmigo. Ya nadie volverá a ver vinculeros y mayorazgos. $Y$ en este mundo que 
yo presento de clérigos, mendigos, escribanos, putas y alcahuetas, lo mejor - con todos sus vicios - eran los hidalgos, lo desaparecido (VALLE-INCLÁN apud ALBERCA; GONZÁLEZ, 2002, p. 126).

O argumento e a citação apresentados por Alberca e González para embasar sua hipótese nos parece insuficiente, porque acreditamos ser evidente que o autor lamenta as questóes da modernidade, apresentando a crise de identidade típica do indivíduo que enfrentava as mudanças advindas da modernidade, mas em nenhum momento se refere especificamente ao carlismo.

Nas páginas seguintes, os biógrafos reconhecem que existe uma crítica ao carlismo na voz do Marqués de Bradomín da Sonata de Invierno (1907), mas que não se deve confundir o discurso derrotista do personagem com a postura pessoal do escritor que, na opiniáo deles, é favorável ao carlismo (ALBERCA; GONZÁLEZ, 2002, p. 127).

Temos aqui então a primeira (e talvez única) referência por parte dos estudiosos da obra de Valle-Inclán ao descompasso entre a postura carlista atribuída a ele e a crítica ao carlismo que Valle-Inclán apresenta na voz dos personagens da trilogia La Guerra Carlista (1908-1909). No entanto, ao invés de problematizar esta questão, os autores da biografia se limitam a pedir que os leitores desconsiderem esta divergência. Isto é justamente o contrário do que propomos neste estudo: defendemos firmemente o olhar crítico sobre a ambiguidade existente entre a defesa pública que Valle-Inclán faz do carlismo e, ao mesmo tempo, a crítica que realiza em seus livros. Entendemos que seu pensamento deve ser observado e analisado a partir desta ambiguidade. Considerando que ele se apresentava como carlista, mas ao mesmo tempo criticava o carlismo, entendemos que o autor queria criar um efeito de estranhamento, despertando no leitor um olhar mais aprofundado e crítico sobre o carlismo e, consequentemente, levando a uma reflexáo sobre os efeitos do conflito. Por mais que defendesse a tradição e o mundo de antes, Valle-Inclán nos leva a refletir sobre a real necessidade do enfrentamento, sobre os interesses políticos em jogo, sobre as vidas perdidas e, principalmente, sobre a falta de sentido que as guerras carlistas vão cobrando ao longo da sua 
duração. Ao mesmo tempo, a postura ambígua, a defesa da tradição e, ao mesmo tempo, a genialidade em criar novas maneiras de narrar situam a Valle-Inclán como pensador da antimodernidade, já que era antigo e moderno, recorrendo à tradiçáo para apresentar o novo e o que nos faz pensar que a atraçáo pelo evento do carlismo ultrapassa qualquer sentimento de tradição ou de família, sendo assimilado em sua vida pessoal e em sua produção artística por ser o evento que melhor representa as questóes dessa modernidade antimoderna na qual ele se movia, ao mesmo tempo em que desconstrói e deforma opinióes e posturas sobre o evento, em um claro processo de esperpentizaçáo.

De fato, a relação carlismo e estética literária é evidente, sendo ressaltada por Alberca e González a relação entre o evento histórico e o modernismo (uma vez que os autores consideram a trilogia La Guerra Carlista pertencente a etapa modernista de Valle-Inclán, segundo as classificaçóes clássicas da obra do autor):

Por otra parte, el carlismo confluía con la estética moderna de fin de siglo, en su versión menos cosmopolita quizá, en una serie de pontos comunes Los encontramos ya en Valle en la etapa de las Sonatas, pero también están presentes en este periodo: la defensa de las sociedades primitivas frente las industrializadas, la preferencia de la armonia de la vida natural a la vida urbana, la superioridad del objeto artesanal sobre el manufacturado en serie, en fin, la exaltación de la belleza por encima de lo moderno. En ambos, en el modernismo y en el carlismo, subyace una visión estática de la historia, una común concepción anti-histórica, consistente en seguir afrontando el futuro como si nada hubiera corrido en el pasado reciente (ALBERCA; GONZÁLEZ, 2002, p. 130)

Podemos concluir que, por mais que Valle-Inclán se apresente na vida pessoal como defensor das tradiçóes e da causa carlista, há uma evidente relaçáo entre o carlismo e as estéticas e os pensamentos vigentes no final do século XIX e início do século XX, o que nos faz pensar que, no que diz respeito ao fazer literário, é o grande atrativo para que Valle-Inclán o incorpore nas suas obras, considerando que se seu interesse fosse apenas político, poderia ter utilizado outros gêneros de escrita para expressar sua filiação ao movimento. 
A outra biografia elaborada por Manuel Alberca se intitula La espada y la palavra. Vida de Valle-Inclán. Foi publicada em 2015 e obteve uma recepçáo muito boa por parte da crítica, a ponto de receber o XXVII Premio Comillas assim que foi publicada. Ainda assim, é uma obra que enfrenta uma grande controvérsia. A pesquisa que originou esta biografia estava sendo realizada em conjunto com Joaquín del Valle-Inclán, mas devido a divergências na metodologia de trabalho os pesquisadores rompem a parceria e a partir desta separaçáo o neto do escritor afirma que Manuel Alberca se apropriou de maneira inadequada da pesquisa de ambos, publicando como se tivesse sido feita apenas por ele. Além disso, Alberca também é acusado de incorrer em fabulaçóes no momento da escrita, o que inviabilizaria sua biografia (PASTORIZA, 2015, p. 02).

Ainda assim, a biografia publicada por Alberca vem sendo considerada pela crítica o documento mais completo publicado sobre Valle-Inclán. Na apresentaçáo do seu texto, ele explica o que considera ser o papel de uma biografia e do biógrafo:

Una biografía debe observar el dificil equilibrio entre información y narración, lo cual es tanto como pedir que el biógrafo sea, además de historiador e investigador, poco menos que novelista. La exhaustividad informativa es una de esas metas por las que el biógrafo daría casi la vida, pero la excesiva información amenaza con saturar al lector, pues ésta tiene un límite, que es la pertinencia y la amenidad.

El biógrafo no debe perder de vista que su objetivo es iluminar a la persona que hay detrás del nombre del autor, artifice de una obra literaria, al tiempo que mostrar cómo se ha formado el hombre y como se ha desarrollado su vida, sin olvidar las claves de su pensamiento político y religioso. El relato biográfico debe incorporar los ingredientes documentales, aportar el máximo de conocimientos racionales, pero sin olvidar que una vida es una suma de estratos intelectuales, materiales y sentimentales. Los detalles e incluso las minucias, cuando se estiman relevantes, deben servir para la comprensión e interpretación del biografiado. El gran reto del biografo es la objetividad, la lucha por la imparcialidad y la verdad, lo cual le aparta tanto de la inquisición justiciera como la actitud hagiográfica. En este sentido he prescindido de las leyendas más o menos favorables, no me he contentado 
con lo consabido, sino que, partiendo de la documentación $y$ de los datos comprobados, he intentado trazar un relato veraz e interpretativo, porque sin narración e interpretación, solo con datos y fechas, ¿qué sería una biografía sino una cronologia? (ALBERCA, 2015, Presentación ${ }^{2}$, p. 3)

O autor, nesta citação, afirma que é necessário certo grau de subjetividade para que a biografia não se resuma a uma simples cronologia. No entanto, entendemos que esta subjetividade precisa surgir do contexto íntimo do biografado para que não haja o risco de se incorrer em invençóes ou fabulaçóes. Mas quando se trata de analisar o pensamento íntimo de Valle-Inclán, existe um grande hiato. Alberca comenta a dificuldade em escrever uma biografia sobre Valle-Inclán já que, por um lado, por ser uma personalidade muito conhecida, não é necessário apresentá-lo através do seu texto, mas, por outro lado, a falta de informaçóes pessoais concretas dificulta o trabalho do biógrafo:

Por un lado, era reservado en lo personal, más que reservado, avaro de su intimidad, que ocultaba, borraba o disimulaba con pistas falsas hasta hacerla impenetrable. Por otro, tenia una tendencia compulsiva a la sobreexposición pública, a buscar la notoriedad, a ser el centro de la escena, del ágora, del café, y ahi brillaba con el máximo esplendor: como un actor al que le gustase cambiar continuamente de papel, don Ramón simultaneaba diferentes máscaras. En resumen, hizo pocas confidencias intimas fiables, $y$ además era fabulador de su propia vida, lo que obstaculiza y frustra las aproximaciones biográficas a partir de sus declaraciones públicas y de las escasas referencias autobiográficas en su obra. Poca ayuda le cabe esperar al biografo de su biografiado, pues Valle-Inclán es el ejemplo de como un escritor evita cualquier confidencia o confesión creíble. Para él, esto era algo execrable y un sintoma de debilidad. (ALBERCA, 2015, Presentación, p. 1)

Joaquín del Valle-Inclán coincide com Alberca neste aspecto, ao afirmar que seu avô não deixou memórias, diários, cartas ou qual-

2 A obra em questão está em formato e-book e a numeração é reiniciada em cada capítulo, sendo necessário, portanto, incluir nas referências a seção ou capítulo ao qual corresponde o texto citado. 
quer tipo de informação íntima que deixasse transparecer seu estado de ânimo ou suas opinióes pessoais (PASTORIZA, 2015, p. 2).

Vemos então que, se para que uma biografia não seja apenas uma cronologia é necessário recorrer a elementos íntimos do biografado, mas Valle-Inclán não deixou transparecer ao longo de sua vida seus sentimentos ou pensamentos íntimos, há uma grande possibilidade de que as biografias recentes sobre o autor, por mais que apresentem a intenção acadêmica da objetividade, ainda estejam incorrendo em fabulaçóes e inferências pessoais por parte dos biógrafos, assim como aconteceu nos primeiros textos.

Alberca também dedica um espaço da sua biografia à relaçáo de Valle-Inclán com o carlismo. Ele afirma que Los Cruzados de la Causa é o primeiro sucesso editorial do autor, provavelmente pela temática do carlismo:

¿Por qué fue tan distinta la recepción de los lectores entre unas y otras? Sin duda por la temática. Los cruzados de la Causa es, por asi decirlo, una obra "apta para todos los públicos": no hay sensualidad, no hay erotismo, tampoco palabras malsonantes ni heroinas libertinas. Por vez primera todo eso se sustituye por el respeto a la tradición y por el heroismo de los carlistas. No parece que calculase obtener resultados comerciales, sino que obedecía sencillamente a la manera sincera que tenía de expresar su convicción tradicionalista actual y la admiración por "la gloriosa epopeya trazada con sin igual valentía por el partido legitimista" (ALBERCA, 2015, cap. 11, p. 44)

Notamos aqui o empenho de Alberca em afirmar que Los cruzados de la Causa é uma obra na qual a tradição carlista é exaltada em uma epopeia. Entretanto, os livros da trilogia La Guerra Carlista não são uma epopeia e sim uma deformação esperpéntica do gênero, ao mesmo tempo em que demonstramos, ao longo deste estudo, em várias ocasiôes, as críticas ao carlismo que transparecem na voz e nas posturas dos personagens, além do sentimento de fracasso que transparece nos três livros. Observamos novamente a discrepância entre o que é afirmado pela crítica e pelos biógrafos e o que transparece nos textos da trilogia. 
Não podemos assumir a postura ingênua de confundir autor e narrador ou ainda autor e personagem de ficção. Deste modo, temos, de acordo com os críticos e os biógrafos, um Valle-Inclán carlista, mas defendemos que não podemos ignorar a crítica ao carlismo e às guerras que transparece nas posturas e nas falas dos personagens da trilogia e por mais que saibamos que não podemos confundir os papéis, sabemos que essa crítica foi formulada pelo gênio de Valle-Inclán. É importante, então, enfatizar a importância de se tentar compreender o porquê desta contradiçãa. Retomamos, então, ao que discutimos anteriormente ao comentar a primeira biografia escrita por Alberca: Valle-Inclán cria um efeito de estranhamento no leitor ao apresentar duas posiçóes conflitantes e evidencia seu caráter antimoderno e esperpêntico no tratamento do tema.

É chamativo o fato dos estudiosos da obra de Valle-Inclán repetirem insistentemente em que a trilogia La Guerra Carlista é uma epopeia elogiativa ao carlismo, sem problematizar as críticas ao conflito que aparecem ao longo do texto. A única menção feita, de maneira reiterativa por muitos, é a fala do Marqués de Bradomín sobre a preferência pela majestade caída que não está presente na trilogia e sim na Sonata de Invierno. Concluímos, então, que a leitura dessa trilogia não está sendo feita com olhar crítico suficiente, uma vez que nos parece evidente que a crítica não consegue desassociar a leitura da trilogia da postura aparentemente carlista que Valle-Inclán apresentava na sua vida pessoal.

Acreditamos que toda tentativa de narrar a vida de Valle-Inclán em forma de biografia, por mais que contribua para o conhecimento do autor, será infrutífera, uma vez que é evidente que Valle-Inclán não se mostrou fora do que era a composição dos seus personagens de ficção e também do seu próprio personagem e, se ele não apresentou marcas de uma vida pessoal, qualquer publicação com este objetivo incorre na ficcionalização ou na fabulação do autor por parte dos biógrafos.

\section{Valle-Inclán e a autoficção esperpéntica}

Consideramos que Valle-Inclán, de maneira consciente, não falava de sua vida íntima nem demonstrava posturas pessoais que não 
estivessem envolvidas em uma aura de histrionismo e fabulação, o que relativiza as possibilidades de interpretaçáo e, ao mesmo tempo, dificulta o entendimento de textos do gênero autobiográfico, sejam biografias, autobiografias ou autoficçóes.

De acordo com Lejeune (2014), a autobiografia é uma “[...] narrativa retrospectiva em prosa que uma pessoa real faz de sua própria existência, quando focaliza sua história individual, em particular a história de sua personalidade" (LEJEUNE, 2014, p. 16). Para o autor, só será autobiografia a obra que preencher ao mesmo tempo as categorias apresentadas, isto é, no que diz respeito à forma da linguagem seja uma narrativa em prosa; que o assunto tratado seja a vida individual de uma personalidade; que a identidade do autor remeta a uma pessoa real e, por último, no que diz respeito ao narrador, estejam definidas a identidade do narrador e do personagem principal, assim como deve apresentar uma perspectiva retrospectiva (LEJEUNE, 2014, p. 16-17).

Valle-Inclán não escreve nenhuma autobiografia, isto é, não publica nenhum livro no qual ele se apresente como figura central ou relate sua vida. Contudo, o autor escreve as Sonatas, conjunto de quatro narrativas (Sonata de Primavera, Sonata de Estio, Sonata de Otoño e Sonata de Invierno) em que narra as Memorias amables del Marqués de Bradomín. O gênero memória é, de acordo com Lejeune, vizinho da autobiografia, mas, para que a relação memória/autobiografia aconteça, é necessário a existência da articulação entre autor, narrador e personagem (LEJEUNE, 2014, p. 17-18). O Marqués de Bradomín é um personagem de ficção, portanto, não é uma autobiografia de Valle-Inclán. Muitas vezes o personagem foi considerado um alter ego do autor devido as semelhanças entre eles, mas qualquer característica de Valle-Inclán percebida na representação de Bradomín é ficcional, não representando assim uma autobiografia:

Hay en Bradomin datos o hechos de la biografía de su autor, pero debidamente ficcionalizados. Comparten comunes orígenes geográficos y nobiliarios, comparten simpatias hacia el carlismo, no exentas en ambos de dosis de escepticismo, sufren los dos la amputación del brazo izquierdo y viajan a los mismos paisajes, reales o soñados. Sin embargo, estos rasgos por si solos no serian suficientes para afirmar que 
Bradomin fuese ni siquiera parcialmente un trasunto de su creador (ALBERCA, 2015, cap. 10, p. 39).

Acreditamos que Bradomín é um personagem de ficção que não representa uma autobiografia de Valle-Inclán, no entanto, é notório que o autor se movimenta de maneira ambígua nesse campo, sem se colocar totalmente como personagem de ficçáo, mas criando um personagem com algumas características próximas às suas, o que leva o leitor a um estado de confusão, não no sentido negativo, ao confundir as duas figuras: a do autor e a do personagem. Novamente vemos o efeito do estranhamento, que vincula o autor às questóes antimodernas.

Segundo Alberca, esta confluência entre Valle-Inclán e Bradomín se acentuou após o autor aceitar o convite da revista modernista Alma Española para escrever um texto autobiográfico e documental. Valle-Inclán, seguindo sua vontade controversa, entrega um texto ficcional, mas com aparência autobiográfica:

El breve relato y el autorretrato resultante están llenos de fantasias e invenciones, y antes que una autobiografía, como cabia esperar, resultó un ejemplo magnifico de mitomanía, de mezcla inconsútil de ficción y con algunos datos biográficos verdaderos, en fin, una mezcla perfecta de realidad y ficción para escamotear la realidad (ALBERCA, 2015, cap. 10, p. 40).

Sendo assim, as Sonatas são as memórias de um personagem de ficção. Bradomín é o retrato do nobre espanhol do final do século XIX: falido, decadente, defensor de uma tradição que não existe mais, mas que é o único ambiente possível para a sua existência. Coincidentemente, Valle-Inclán também assume para si a mesma imagem de nobre decadente arraigado ao abolengo da tradição, do nome e de um mundo que náo existe mais. Ao apresentar o personagem Bradomín na ficção, automaticamente associa-se um ao outro. De maneira significativa, entendemos também que, ao criticar a nobreza vazia da Espanha da sua época, através da figura de Bradomín, Valle-Inclán critica a si mesmo. 
Bradomín é o don juan que não obtém sucesso em suas conquistas, o nobre falido, o cavalheiro feio. Todas essas características contradizem a imagem estabelecida de um nobre cavalheiro, o que nos mostra que Valle-Inclán deforma o conceito de cavalheiro, em outras palavras, submete o personagem ao processo de esperpentização que estará presente em maior ou menor grau ao longo de toda a sua obra. Paralelamente, ao vir de família nobre, estar falido, apresentar uma imagem desalinhada, Valle-Inclán também subverte, na sua vida, a imagem da nobreza, sendo ele mesmo um exemplo do processo de esperpentizaçâo.

Para submeter-se a esse sistema de deformação sistemática de si mesmo, Valle-Inclán se insere no campo da autoficção. Para Alberca (2007), a autoficção é o romance no qual o protagonista de uma obra aparentemente de ficção adota o nome do autor real que assina o livro (ALBERCA, 2007, p. 15). Segundo o autor, a autoficção está fundamentada na identidade visível ou reconhecível do autor, que será ao mesmo tempo narrador e personagem do seu relato:

En este contexto, identidad no quiere decir necesariamente esencia, sino un hecho aprensible directamente en el enunciado, en el cual percibimos la correspondencia referencial entre el plano del enunciado y el de la enunciación, entre el protagonista y su autor, como resultado siempre de la transfiguración literaria (ALBERCA, 2007, p. 31).

Podemos considerar então que a autoficção pode oferecer uma possibilidade de diálogo entre escritor e leitores, no qual o escritor se coloca como personagem de ficção, requerendo para si todas as prerrogativas que conformam um personagem. A autoficção também contribui para situar o escritor em um lugar de ambiguidade e de subversão de limites e gêneros:

La autoficción dibuja un original espacio autobiográfico y novelesco en el que se comprueba que los relatos que se acogen a esta posibilidad, como también un contingente importante de la poesia y otras manifestaciones artísticas actuales, mezclan las fronteras entre lo real y lo inventado, demostrando la fácil permeabilidad creadora entre ambas. Sin embargo, nuestro análisis no olvida algo que normalmente no se tiene 
en cuenta: dicha permeabilidad o mezcla es posible o existe gracias a la diferencia y a la frontera, sin las cuales no se podrian mesclar los territorios distintos sin transgredir sus limites (ALBERCA, 2007, p. 32).

Vemos, nessa citação, que a autoficção possibilita um espaço privilegiado de criação que flexibiliza a fronteira entre o real e o inventado, ou seja, entre a realidade ${ }^{3}$ e a ficção, no entanto, esta criação só ocorre onde e quando esta fronteira está flexibilizada. A autoficção promove, então, a ideia de que a narrativa não é, necessariamente, ficção, podendo ser uma forma de ordenar e explicar a vida (ALBERCA, 2007, p. 47).

Neste sentido, a autoficção permite a invenção performática de si próprio:

Lo ponen en escena y lo hacen intervenir como un ser autónomo que ha invadido o se apropiado del cuerpo $y$ la personalidad del artista. El objetivo de la performance consiste en mezclar y en confundir los limites de lo real y lo inventado y consiguen (si es que es lo que buscaban) que no podamos determinar cuánto de juego, de búsqueda identitaria, de afirmación o de reivindicación personal hay en sus presentaciones (ALBERCA, 2007, p. 34).

É justamente neste lugar, da invenção de um personagem ficcional, que situamos a Valle-Inclán. Vimos, no estudo das biografias sobre o autor, que ele, de maneira consciente, não transparecia nenhuma informaçáo pessoal. Ao mesmo tempo, foi construindo, pouco a pouco, uma imagem ficcional, teatral, na qual se desenvolvia na vida real.

É notório que Valle-Inclán, ao longo da sua vida, se autoficcionaliza, isto é, cria um personagem ficcional no qual atua. Esta criação envolvia a aparência física (cabelo, barba, óculos, vestuário), o comportamento (excêntrico e histriônico), a linhagem (requeria uma ascendência nobre, mas decadente) e, possivelmente, as ideologias.

3 Não nos deteremos na discussão teórica dos conceitos de realidade e/ou representação da realidade, entendendo realidade aqui, na citaçâo e no seu comentário, simplesmente como o contraponto da ficção. 
Por mais que os estudiosos da obra e da vida de Valle-Inclán afirmem categoricamente sua filiação carlista, é necessário considerar que existe a possibilidade de que esta postura também forme parte da confecção do personagem Valle-Inclán.

O mais significativo no processo de autoficcionalização realizado por Valle-Inclán é o lugar onde ele se desenvolve. Valle-Inclán não transforma a si mesmo em personagem no papel, em um dos seus romances. Ele se transforma em personagem na vida real, no dia a dia, no mesmo nível de realidade dos seus leitores. Com isso, Valle-Inclán transgrede os lugares tradicionais de ficção e ao invés de conferir características autobiográficas aos personagens das obras que escreve, ele assume, na vida real, atitudes ficcionais. Vemos, então, que a produçáo artística do autor ultrapassa a escrita de livros e peças de teatro. Seu projeto ficcional requeria também a elaboração de um outro tipo de ficção, teatral e narrativo ao mesmo tempo, interpretado por ele mesmo no dia a dia.

\section{Considerações finais}

Observamos a natureza antimoderna de Valle-Inclán, uma vez que o autor cria uma maneira totalmente inovadora de narrar, ficcionalizando a própria vida, mas o faz construindo um personagem antigo, tradicional, articulando assim na sua criação o pressuposto do antigo para tratar do novo, pressuposto da antimodernidade.

Ressaltamos também que, ao mesmo tempo em que constrói seu personagem na vida real, desconstrói o papel do escritor (que passa a ser personagem), desvirtua os locais de produção da ficção (que deixa de ser apenas o livro e passa a ser também no mesmo nível de realidade do leitor), ultrapassa os gêneros literários escritos (narrativa e teatro).

Ao mesmo tempo em que realiza estas desconstruçóes, Valle-Inclán altera ou deforma a imagem do escritor, transformando-o em personagem e, nesta representação do autor personificado, a aparência física e o comportamento não são os esperados por parte de um escritor tradicional, são atitudes e aparência escandalosos e grotescos. Tanto a autoficcionalização de Valle-Inclán como a representação de sua aparência e suas atitudes despertam estranhamento no leitor 
e, consequentemente, situa a Valle-Inclán na estética do esperpento. Valle-Inclán está, portanto, esperpentizando a si mesmo, assumindo uma máscara grotesca na qual se movimenta como autor de ficção.

Podemos concluir, então, que no que diz respeito aos gêneros ficcionais da escrita do eu, Valle-Inclán não publica nenhuma autobiografia ou autoficção. No entanto, a ambiguidade na construção do personagem Marqués de Bradomín alimentou a crença de que o personagem era o alter ego do autor. De fato, Valle-Inclán se autoficcionaliza, mas não através de Bradomín e sim na construção de um personagem encenado na vida real. Para isso, o autor cria uma aura de histórias ficcionais sobre si mesmo e omite propositalmente informaçóes íntimas e verídicas, fazendo com que a sua atuação social seja ficcional. Ao mesmo tempo, os elementos que conformam o seu personagem náo condizem com a imagem padrão de um escritor ou de um nobre, sendo uma deformação dos dois, o que nos leva a concluir que Valle-Inclán aplica o processo de deformação sistemática do esperpento em si mesmo, como uma forma de autoficção.

\section{Referências bibliográficas}

ALBERCA, M. El pacto ambiguo. De la novela autobiográfica a la autoficción. Madrid: Editorial Biblioteca Nueva, 2007.

. La espada y la palabra. Vida de Valle-Inclán. Barcelona: Tusquets Editores, 2015.

ALBERCA, M.; GONZÁLEZ, C. Valle-Inclán. La fiebre del estilo. Madrid: Espasa Calpe, 2002.

ARFUCH, L. O espaço biográfico: dilemas da subjetividade contemporânea. Tradução de Paloma Vidal. Rio de Janeiro: EdUERJ, 2010.

CARINO, J. A biografia e sua instrumentalidade educativa. Educação \& Sociedade, ano XX, n. 67, 1999. Disponível em <http://www.scielo. br/pdf/es/v20n67/v20n67a05.pdf>. Acesso em: 24 jan. 2017.

EFE. Nieto de Valle-Inclán: "Era muy reservado, apenas decía lo que sentía”. El Confidencial. Disponível em: <http://www.elconfidencial. com/ultima-hora-en-vivo/2015-11-21/nieto-de-valle-inclan-era-muy-reservado-apenas-decia-lo-que-sentia_750947/>. Acesso em: 10 mai. 2017. 
LEJEUNE, P. O pacto autobiográfico: de Rousseau à Internet. 2a. ed. Belo Horizonte: Editora UFMG, 2014.

MARTÍNEZ SÁURA, S. Espira, Lorca, Unamuno y Valle-Inclán en la poética de su tempo. 1a. ed. Madrid: Ediciones Libertarias, 1998.

PASTORIZA, F. R. Ramón del Valle-Inclán: Genial, antiguo y moderno. Periodistas en español.com. 2015. Disponível em: <http:// periodistas-es.com/ramon-del-valle-inclan-genial-antiguo-y-moderno-59120>. Acesso em: 20 fev. 2017.

VALLE-INCLÁN, J. del. (ed.). Entrevistas. Alianza Editorial: Madrid, 2000.

VILLENA, L. A. de. Ramón del Valle-Inclán. Genial, antiguo y moderno. El cultural. 2015. Disponível em: <http://www.elcultural.com/ revista/letras/Ramon-del-Valle-Inclan-Genial-antiguo-y-moderno/37160>. Acesso em: 14 mai. 2017.

Raquel da Silva Ortega. Professora Adjunta do Departamento de Letras e Artes da Universidade Estadual de Santa Cruz. Doutora em Letras Neolatinas pela Universidade Federal do Rio de Janeiro (UFRJ). Possui Mestrado em Letras Neolatinas - Língua Espanhola e Literaturas Hispânicas pela Universidade Federal do Rio de Janeiro (2004) e Graduação em Letras Português/Espanhol pela Universidade do Estado do Rio de Janeiro (2001). Professora na Especialização em Didática de Espanhol como Língua Estrangeira na Educaçáo Básica, da Uesc. Possui experiência no ensino e pesquisa de Língua Espanhola, Cultura e Literaturas Hispânicas, atuando nas áreas de ensino de literatura e cultura estrangeira. E-mail: rsortega@uesc.br

Recebido em: 13/05/2018

Aceito em: 20/09/2018 